\title{
Effect of Caffeic Acid Phenethyl Ester Provision on Fibroblast Growth Factor-2, Matrix Metalloproteinase-9 Expression, Osteoclast and Osteoblast Numbers during Experimental Tooth Movement in Wistar Rats (Rattus norvegicus)
}

\author{
Ida Bagus Narmada ${ }^{1}$ Paristyawati Dwi Putri ${ }^{1}$ Lucky Lucynda ${ }^{1}$ Ari Triwardhani ${ }^{1}$ \\ I Gusti Aju Wahju Ardani $\quad$ Alexander Patera Nugraha ${ }^{1}$
}

${ }^{1}$ Department of Orthodontics, Faculty of Dental Medicine, Universitas Airlangga, Surabaya, Indonesia
Address for correspondence Ida Bagus Narmada, DDS, M.Orth(C), Department of Orthodontic, Faculty of Dental Medicine, Universitas Airlangga, Campus A, Jl Prof Dr Moestopo, No. 47, Surabaya 60132, East Java, Indonesia (e-mail: ida-b-n@fkg.unair.ac.id).

\author{
Abstract \\ Keywords \\ - caffeic acid phenethyl \\ ester \\ - experimental tooth \\ movement \\ - fibroblast growth \\ factor-2 \\ - matrix \\ metalloproteinase-9 \\ - medicine
}

Objectives To investigate the effect of caffeic acid phenethyl ester (CAPE) provision on matrix metalloproteinase-9 (MMP-9), fibroblast growth factor-2 (FGF-2) expression, osteoclast and osteoblast numbers during experimental orthodontic tooth movement (OTM) in male Wistar rats (Rattus norvegicus).

Materials and Methods Forty-eight healthy male Wistar rats (R. norvegicus), 16 to 20 weeks old with 200 to $250 \mathrm{~g}$ body weight (bw) were divided into several groups as follows: K1: OTM for 3 days; K2: OTM for 7 days; K3: OTM for 14 days; KP1: OTM and CAPE for 3 days; KP2: OTM and CAPE for 7 days; and KP3: OTM and CAPE for 14 days. A nickel titanium closed coil spring $8.0 \mathrm{~mm}$ long with $10 \mathrm{~g} / \mathrm{mm}^{2}$ was installed between the upper left first molar and upper central incisor to move molar mesially. CAPE provision with a dose of $20 \mathrm{mg} / \mathrm{kg}$ bw of animal studies was done per orally. Immunohistochemistry was done to examine MMP-9 expression and osteoclast number in compression side as well as FGF-2 expression and osteoblast number in tensile side of the OTM.

Statistical Analysis One-way analysis of variance test and Tukey's honest significant difference test were performed to determine the difference between the groups $(p<0.05)$.

Results MMP-9 expression and osteoclast numbers in the compression side were significantly different between the groups. Similarly, FGF-2 expression and osteoclast numbers in the tensile side were significantly different between the groups.

Conclusions CAPE provision during OTM increases the number of osteoblasts and the FGF-2 expression significantly in the tensile side. Osteoclast numbers and MMP-9 expression significantly decrease in the compression side. published online January 28, 2021
DOI https://doi.org/ $10.1055 / \mathrm{s}-0040-1718640$ ISSN 1305-7456.
(C) 2021. European Journal of Dentistry.

This is an open access article published by Thieme under the terms of the Creative Commons Attribution-NonDerivative-NonCommercial-License, permitting copying and reproduction so long as the original work is given appropriate credit. Contents may not be used for commercial purposes, or adapted, remixed, transformed or built upon. (https://creativecommons.org/licenses/by-nc-nd/4.0/)

Thieme Medical and Scientific Publishers Pvt. Ltd., A-12, 2nd Floor, Sector 2, Noida-201301 UP, India 


\section{Introduction}

Teeth can move in the alveolar bone due to the inducement of orthodontic force in the form of mechanical pressure. ${ }^{1}$ The inducement of orthodontic forces will initiate cellular and biochemical activities, accompanied by the remodeling of periodontal ligaments and alveolar bone. ${ }^{2}$ The application of orthodontic forces for malocclusion treatment will begin the cellular and molecular signaling and regulation in the periodontal tissue. Fibroblasts, osteoblasts, osteoclasts, and macrophages are types of cells that play an interactive role in bone remodeling. ${ }^{3}$

During orthodontic tooth movement (OTM), the changes that occur in the periodontal area depend on the force, direction, and duration of OTM. ${ }^{4}$ OTM with heavy force applied compresses periodontal tissue, which causes capillary thrombosis and cell apoptosis. The heavy force will increase root resorption during OTM. Previous studies have shown a positive correlation between prolonged OTM duration and tooth root resorption. ${ }^{5}$

Alveolar bone remodeling occurs due to osteoclast and osteoblast activities. Those cells function as a coordinated mechanism to induce the resorption and apposition of the alveolar bone in response to stress and mechanical loads. ${ }^{6}$ On the compression side during OTM, alveolar bone apposition occurs due to osteoblast activity. Osteoblasts play an important role in new bone formation in the tensile area of OTM. ${ }^{7}$ There are molecular markers related to osteoblast differentiation and activity, such as bone alkaline phosphatase (BALP), runt-related transcription factor-2 (RUNX2), osterix, osteocalcin, osteonectin, and osteopontin. ${ }^{8-12}$

Growth factors also play an important role in osteoblast maturation and activity, such as vascular endothelial growth factor and fibroblast growth factor-2 (FGF-2). FGF-2 regulates bone formation and osteoblast differentiation. ${ }^{6,13}$ The decrease in FGF-2 in the osteoblast will reduce osteoblast proliferation through the reduction of BALP secretion. ${ }^{14}$ In the initial stage of OTM, osteoblast markers increase in the tensile side and decrease in the compression side. One of the osteoblast activity molecular markers in the tensile side during OTM is FGF-2, which increases gradually on days 3,7 , and $14 . .^{15,16}$

Meanwhile, in the compression side, bone resorption occurs due to osteoclast activity during OTM. Osteoclasts are multinucleated giant cells derived from hematopoietic stem cells. Macrophages, as progenitors of osteoclasts and odontoclasts that appear in the early phase of OTM, could increase bone and root resorption. Macrophages also produce proinflammatory mediators such as tumor necrosis factor (TNF)- $\alpha$ in response to OTM. ${ }^{17}$ TNF- $\alpha$ can induce osteoclast activation and maturation, which can induce bone resorption during OTM. ${ }^{18}$ Alveolar bone resorption by osteoclasts causes demineralization of the inorganic bone matrix by acids and degradation of the organic bone matrix by cathepsin $\mathrm{K}$ and matrix metalloproteinase (MMP). ${ }^{19}$

The highest MMP expression was found in the compression side during OTM, which included MMP-9 that was expressed during the inflammatory response. MMP-9 expression is most abundant in the compression side involved in bone resorption..$^{20}$ Efforts to improve alveolar bone remodeling during OTM should be made to obtain optimal treatment results, reduce the duration of OTM, and prevent the side effects of OTM, such as orthodontic-induced root resorption (OIRR). ${ }^{10,21,22}$

Caffeic acid phenethyl ester (CAPE), which is contained in propolis, may be useful for controlling inflammation during OTM and preventing OIRR. CAPE serves as an anti-inflammatory that can inhibit cyclooxygenase. ${ }^{23}$ CAPE can inhibit the release of proinflammatory cytokines and increase the production of anti-inflammatory cytokines. ${ }^{24}$ CAPE administration in the tooth extraction of the animal model resulted in the accelerated healing of alveolar bone defects. ${ }^{25}$ An increase in new bone formation was found after CAPE provision during the palatine suture postinducement by rapid maxillary expander device. ${ }^{26}$ The polyethylene particle-induced calvaria osteolysis in murine model can significantly inhibited by CAPE administration..$^{27}$ The CAPE has antioxidant and anti-inflammatory activities that ameliorate periodontal disease through the reduction of reactive oxidative stress (ROS). ${ }^{24}$ The antioxidant ability of CAPE directly or indirectly inhibits the ROS activity, resulting in osteoblast differentiation maturation and activity. Thus, CAPE may inhibit osteoclast activity. ${ }^{25}$ Furthermore, the purpose of this study is to investigate the effect of CAPE provision on MMP-9 expression and osteoclast numbers in the compressed side as well as FGF-2 expression and osteoblast numbers in the tensile side during experimental tooth movement in male Wistar rats (Rattus norvegicus) as animal model.

\section{Materials and Methods}

\section{The Experimental Study Design and Ethical Clearance Approval}

An analytical, experimental study with a posttest only control group design was performed. The sample consisted of 48 healthy male Wistar rats ( $R$. norvegicus), 16 to 20 weeks old with 200 to $250 \mathrm{~g}$ body weight (bw) assigned into six groups randomly. The groups were: K1: control group (OTM for 3 days); K2: control group (OTM for 7 days); K3: control group (OTM for 14 days); KP1: treatment group (OTM and CAPE for 3 days); KP2: treatment group (OTM and CAPE for 7 days); and KP3: treatment group (OTM and CAPE for 14 days). The sample size was determined by means of Lameshow's sample size formula. The health ethical clearance commission, Faculty of Dental Medicine, Universitas Airlangga approved this study for experimental animal use with approval number 036/HRECC.FODM/I/2020.

\section{Preparation and Provision of Caffeic Acid Phenethyl Ester \\ The phenethyl caffeate $\left(\mathrm{C}_{17} \mathrm{H}_{16} \mathrm{O}_{4}\right)$ (CAPE) (cat no. 104594-70-9, Tokyo Chemical Industry Co., Ltd., Tokyo, Japan) was dis- solved in distilled water at a dose of $20 \mathrm{mg} / \mathrm{kg}$. The solution was administered once a day by means of oral gavage for 1,7 , and 14 days depending on the experimental group.}

\section{Experimental Tooth Movement in the Animal Model}

All experimental animals used in this study were adapted to the new environment for 7 days to minimize stress due to the 
new environment. Polycarbonate cages $(0.90 \times 0.60 \times 0.60 \mathrm{~m})$ were used to maintain each rat in a controlled environment in 12-hour light/dark cycle at a steady temperature of $25^{\circ} \mathrm{C}$ and controlled humidity of $50 \%$. All experimental animals were given standard pellet feed and tap ad libitum drinking water. Every day, the animal cages were examined for food and beverage consumption and fecal characteristics, and cage hygiene was maintained.

Before and after treatment, each animal's weight was tested using a digital scale. Ketamine $(100 \mathrm{mg} / \mathrm{kg}$ bw) and xylazine ( $5 \mathrm{mg} / \mathrm{kg}$ bw) were used to anesthetize the experimental animals to minimize animal suffering during the installation of the OTM appliance. The experimental tooth movement was induced in the animal models by means of a nickel titanium closed coil spring $8.0 \mathrm{~mm}$ long (American Orthodontics [AO], United States) with $10 \mathrm{~g} / \mathrm{mm}^{2}$, which was installed between the upper left first molar and upper central incisor to move the molar mesially. A 0.07 stainless steel ligature wire was used to maintain maxillary central incisive and first molar (AO, United States). ${ }^{28}$ The provision of CAPE with a dose of $20 \mathrm{mg} / \mathrm{kg}$ bw was performed per orally by oral gavage.

All samples were then sacrificied according to the specified days (days 1,7 , and 14 ) according to their respective groups using the cervical dislocation method to minimize the animal's suffering during the termination process. The afflicted premaxilla tissue was extracted and immersed for 4 days in $10 \%$ formalin (OneMed; Sidoarjo, Indonesia) for the fixation process. After the fixation process, the premaxilla was immersed in the 10\% EDTA (OneMed) for 2 months. The sample then subjected to tissue processing, dehydrated in a graded series of ethanol, and embedded in paraffin. Sections were cut at $5 \mu \mathrm{m}$ rotary microtome (RM2235; Leica, United States). Paraffin ribbons were flattened in a water bath at $40^{\circ} \mathrm{C}$ and collected into Polysine microscope slides (Thermo Scientific, United States) prior to drying at $60^{\circ} \mathrm{C}$ for 16 days (Sakura Heater; Tokyo, Japan). ${ }^{29}$

\section{Immunohistochemistry Staining}

Antibody monoclonal of FGF-2 (1:200 dilution) to detect FGF-2 expression and MMP-9 (1:200 dilution) to detect MMP-9 expression were used in this study. Additionally, 3.3'-diaminobenzidine stain kit (Sigma Aldrich, United States) was used for immunohistochemistry staining, and hematoxylineosin (HE) was used for counterstaining (Sigma Aldrich). Osteoblasts and osteoclasts were stained by means of $\mathrm{HE}$ staining. The observation and calculation of the number of osteoblasts and FGF-2 expression in the alveolar bone were done in the tensile side. Meanwhile, the observation and calculation of the number of osteoclasts and MMP-9 expression in the alveolar bone were conducted in the compression side. The observation and calculation were performed manually by two observers in five perspective fields of view by utilizing a Nikon H600L light microscope (Japan) at $\times 400$ magnification.

\section{Statistical Analysis}

Analysis of the research data was preceded by a normality test using the Kolmogorov-Smirnov's test $(p>0.05)$, after which the homogeneity test using the Levene's statistic test $(p>0.05)$ was conducted. One-way analysis of variance test was conducted to determine whether there is a difference between the two treatment groups $(p<0.05)$. Furthermore, to find out the differences in each treatment group, Tukey's honest significant difference test was performed $(p<0.05)$. The Statistical Package for Social Science (SPSS) 20.0 version (IBM Corporation; Illinois, Chicago, United States) software was used in this study to analyze the data.

\section{Results}

The provision of CAPE at selected doses did not lead to any general toxicity, edema, death, or changes in the bw of the animal model. The positive expression of MMP-9 in the osteoclast of the Wistar rat's alveolar bone during OTM in the compression side was detected in all experimental groups (-Fig. 1). The histological section results showed that osteoclast was found in all experimental groups ( - Fig. 2). All data obtained in this study were homogenous and normally distributed $(p>0.05)$. The highest expression of MMP-9 was

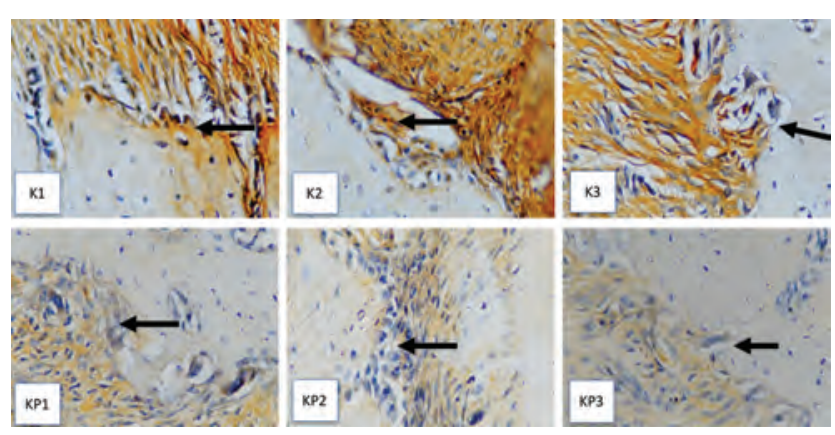

Fig. 1 The immunohistochemistry result of MMP-9 expression in the osteoclast of the Wistar rat's alveolar bone during OTM in the compression side. The positive expression of MMP-9 in the osteoclast is shown as a stained brown color (black arrow) by means of inverted light microscope at $\times 400$ magnification. K1: OTM for 3 days; K2: OTM for 7 days; K3: OTM for 14 days; KP1: OTM and CAPE for 3 days; KP2: OTM and CAPE for 7 days; and KP3: OTM and CAPE for 14 days. CAPE, caffeic acid phenethyl ester; MMP-9, matrix metalloproteinase-9; OTM, orthodontic tooth movement.

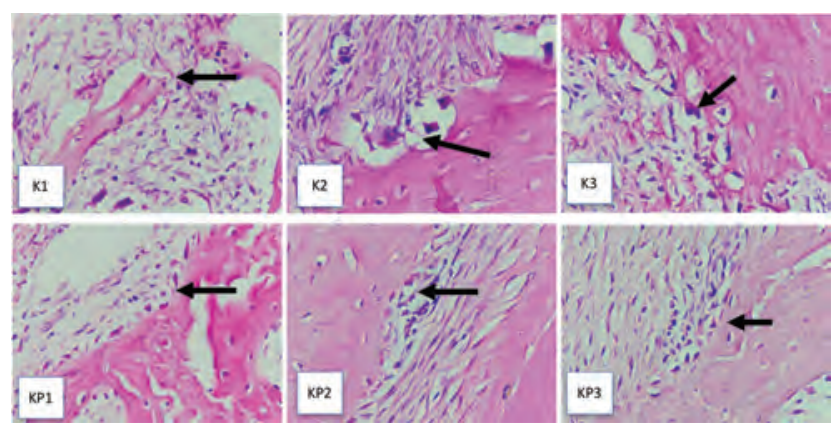

Fig. 2 The histological section of osteoclast in the Wistar rat's alveolar bone during OTM in the compression side. The morphology of the osteoclast is shown as a multinucleated giant cell surrounded by bone resorption area (black arrow) by means of inverted light microscope at $\times 400$ magnification. K1: OTM for 3 days; K2: OTM for 7 days; K3: OTM for 14 days; KP1: OTM and CAPE for 3 days; KP2: OTM and CAPE for 7 days; and KP3: OTM and CAPE for 14 days. CAPE, caffeic acid phenethyl ester; OTM, orthodontic tooth movement. 
found in the K1 group, while the lowest MMP-9 expression was detected in the KP3 group. The highest osteoclast number was found in the $\mathrm{K} 3$ group, while the lowest osteoclast number was detected in the KP3 group. There was a significant difference in MMP-9 expression and osteoclast numbers in the compression side between the groups $(p<0.05)$ (-Table 1). The comparison of MMP-9 expression and osteoclast numbers in the compression side between the groups is displayed in - Table 2.

The positive expression of FGF-2 in the osteoblast of the Wistar rat's alveolar bone during OTM in the tensile side was

Table 1 Mean and SD of osteoclast number and MMP-9 expression in the compression side in each group

\begin{tabular}{|c|c|c|c|c|c|}
\hline \multirow[t]{3}{*}{ Group } & \multirow[t]{3}{*}{$n$} & \multicolumn{4}{|c|}{ Compression side } \\
\hline & & Osteoclast & \multirow[t]{2}{*}{ ANOVA } & MMP-9 & \multirow[t]{2}{*}{ ANOVA } \\
\hline & & Mean \pm SD & & Mean \pm SD & \\
\hline K1 & 7 & $12.14 \pm 0.69$ & \multirow[t]{6}{*}{$0.001^{\mathrm{a}}$} & $11.57 \pm 1.27$ & \multirow[t]{6}{*}{$0.001^{\mathrm{a}}$} \\
\hline KP1 & 7 & $9.43 \pm 0.98$ & & $8.86 \pm 0.76$ & \\
\hline K2 & 7 & $15.29 \pm 0.76$ & & $14.43 \pm 0.98$ & \\
\hline KP2 & 7 & $7 \pm 0.816$ & & $7.86 \pm 0.69$ & \\
\hline K3 & 7 & $13.71 \pm 1.11$ & & $16.14 \pm 1.35$ & \\
\hline KP3 & 7 & $5.714 \pm 0.76$ & & $5.714 \pm 0.49$ & \\
\hline
\end{tabular}

Abbreviations: ANOVA, analysis of variance; MMP-9, matrix metalloproteinase-9; SD, standard deviation.

aSignificant at $p$-value $=0.05$.

Table 2 The result of Tukey's HSD test of MMP-9 expression and osteoclast number between the groups in compression side

\begin{tabular}{|c|c|c|c|}
\hline \multirow{2}{*}{\multicolumn{2}{|c|}{$\begin{array}{l}\text { Comparison } \\
\text { between the } \\
\text { groups }\end{array}$}} & \multicolumn{2}{|c|}{ Compression side } \\
\hline & & $\begin{array}{l}\text { MMP-9 } \\
\text { Expression } \\
p \text {-Value }\end{array}$ & $\begin{array}{l}\text { Osteoclast number } \\
p \text {-Value }\end{array}$ \\
\hline \multirow{5}{*}{ K1 } & K2 & $\cap \Omega \cap 1$ a & $0 \Omega 1^{a}$ \\
\hline & K3 & $0.001^{\mathrm{a}}$ & $0.01^{\mathrm{a}}$ \\
\hline & KP1 & $0.01^{\mathrm{a}}$ & $0.01^{a}$ \\
\hline & KP2 & $0.01^{\mathrm{a}}$ & $0.01^{\mathrm{a}}$ \\
\hline & KP3 & $0.01^{\mathrm{a}}$ & $0.01^{a}$ \\
\hline \multirow[t]{4}{*}{ K2 } & K3 & $0.016^{a}$ & $0.01^{\mathrm{a}}$ \\
\hline & KP1 & $0.01^{\mathrm{a}}$ & $0.01^{\mathrm{a}}$ \\
\hline & KP2 & $0.01^{\mathrm{a}}$ & $0.01^{\mathrm{a}}$ \\
\hline & KP3 & $0.01^{\mathrm{a}}$ & $0.01^{a}$ \\
\hline \multirow[t]{3}{*}{ K3 } & KP1 & $0.01^{\mathrm{a}}$ & $0.01^{\mathrm{a}}$ \\
\hline & KP2 & $0.01^{\mathrm{a}}$ & $0.01^{\mathrm{a}}$ \\
\hline & KP3 & $0.01^{\mathrm{a}}$ & $0.01^{\mathrm{a}}$ \\
\hline \multirow[t]{2}{*}{ KP1 } & KP2 & $0.042^{\mathrm{a}}$ & $0.01^{\mathrm{a}}$ \\
\hline & KP3 & $0.01^{\mathrm{a}}$ & $0.01^{a}$ \\
\hline KP2 & KP3 & $0.01^{\mathrm{a}}$ & $0.01^{\mathrm{a}}$ \\
\hline
\end{tabular}

Abbreviations: HSD, honest significant difference; MMP-9, matrix metalloproteinase-9.

asignificant at $p$-value $=0.05$. detected in all experimental groups ( - Fig. 3 ). The histological section results showed that osteoblast was found in all experimental groups (-Fig. 4). The highest expression of FGF-2 was found in the KP3 group, while the lowest FGF-2 expression was detected in the $\mathrm{K} 1$ group. The highest osteoblast number was found in the KP3 group, while the lowest osteoblast number was detected in the $\mathrm{K} 1$ group. There was a significant difference in FGF-2 expression and osteoblast numbers in the tensile side between the groups $(p<0.05)$ (-Table 3). The comparison of FGF-2 expression and the osteoblast numbers in the tensile side between groups is displayed in - Table 4.

\section{Discussion}

This study was conducted with the administration of CAPE during OTM in animal models. A force of as much as $10 \mathrm{~g} / \mathrm{mm}^{2}$ induced by means of closed coil spring was applied for 4 , 7 , or 14 days. Optimum and effective force to induce experimental tooth movement in rats was less than $10 \mathrm{~g} / \mathrm{mm}^{2} .^{10,30} \mathrm{In}$ this
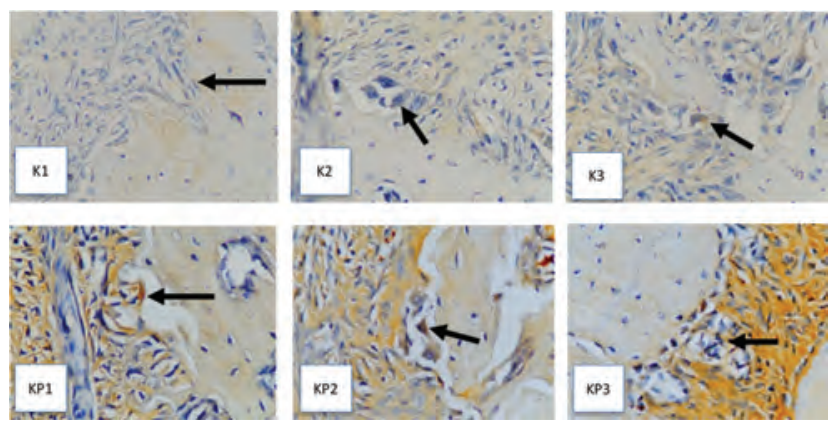

Fig. 3 The immunohistochemistry result of FGF-2 expression in the osteoblast of the Wistar rat's alveolar bone during OTM in the tensile side. The positive expression of MMP-9 in the osteoblast is shown as a stained brown color (black arrow) by means of inverted light microscope at $\times 400$ magnification. K1: OTM for 3 days; K2: OTM for 7 days; K3: OTM for 14 days; KP1: OTM and CAPE for 3 days; KP2: OTM and CAPE for 7 days; and KP3: OTM and CAPE for 14 days. CAPE, caffeic acid phenethyl ester; FGF-2, fibroblast growth factor-2; MMP9, matrix metalloproteinase-9; OTM, orthodontic tooth movement.

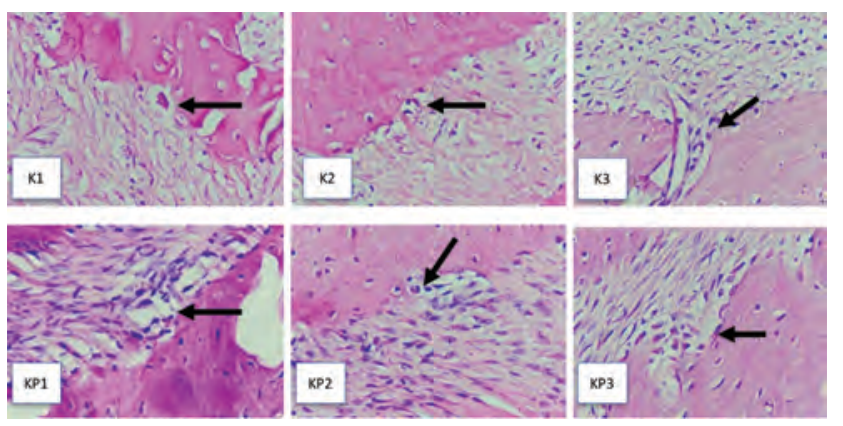

Fig. 4 The histological section of osteoblast in the Wistar rat's alveolar bone during OTM in the compression side. The morphology of the osteoblast is shown as a round cell attached on the bone surfaces (black arrow) by means of inverted light microscope at $\times 400$ magnification. K1: OTM for 3 days; K2: OTM for 7 days; K3: OTM for 14 days; KP1: OTM and CAPE for 3 days; KP2: OTM and CAPE for 7 days; and KP3: OTM and CAPE for 14 days. CAPE, caffeic acid phenethyl ester; OTM, orthodontic tooth movement. 
Table 3 Mean and SD of osteoblasts number and FGF-2 expression in the tensile side in each group

\begin{tabular}{|c|c|c|c|c|c|}
\hline \multirow[t]{3}{*}{ Group } & \multirow[t]{3}{*}{$n$} & \multicolumn{4}{|c|}{ Tensile side } \\
\hline & & Osteoblast & \multirow[t]{2}{*}{ ANOVA } & FGF-2 & \multirow[t]{2}{*}{ ANOVA } \\
\hline & & Mean \pm SD & & Mean \pm SD & \\
\hline K1 & 7 & $6.29 \pm 3.4$ & \multirow[t]{6}{*}{$0.001^{\mathrm{a}}$} & $6.57 \pm 1.9$ & \multirow[t]{6}{*}{$0.001^{\mathrm{a}}$} \\
\hline KP1 & 7 & $9 \pm 1.29$ & & $9.71 \pm 1.6$ & \\
\hline K2 & 7 & $7.43 \pm 2.23$ & & $6.86 \pm 1.86$ & \\
\hline KP2 & 7 & $13.71 \pm 3.15$ & & $15 \pm 2.77$ & \\
\hline K3 & 7 & $8.71 \pm 2.36$ & & $9.43 \pm 1.99$ & \\
\hline KP3 & 7 & $15.86 \pm 2.61$ & & $15.43 \pm 2.57$ & \\
\hline
\end{tabular}

Abbreviations: ANOVA, analysis of variance; FGF-2, fibroblast growth factor-2; SD, standard deviation.

aSignificant at $p$-value $=0.05$.

Table 4 The result of Tukey's HSD test of FGF-2 expression and osteoblast number between groups

\begin{tabular}{|c|c|c|c|}
\hline \multirow{2}{*}{\multicolumn{2}{|c|}{$\begin{array}{l}\text { Comparison } \\
\text { between the groups }\end{array}$}} & \multicolumn{2}{|c|}{ Tensile side } \\
\hline & & \multirow{2}{*}{$\begin{array}{l}\text { FGF-2 } \\
\text { expression } \\
p \text {-Value } \\
\end{array}$} & \multirow{2}{*}{$\begin{array}{l}\begin{array}{l}\text { Osteoblast } \\
\text { number }\end{array} \\
p \text {-Value }\end{array}$} \\
\hline & & & \\
\hline \multirow[t]{5}{*}{ K1 } & $\mathrm{K} 2$ & $0.001^{\mathrm{a}}$ & $0.015^{\mathrm{a}}$ \\
\hline & K3 & $0.001^{\mathrm{a}}$ & $0.001^{\mathrm{a}}$ \\
\hline & KP1 & $0.01^{a}$ & 0.235 \\
\hline & KP2 & 1 & 0.895 \\
\hline & KP3 & 1 & 1 \\
\hline \multirow[t]{4}{*}{$\mathrm{K} 2$} & K3 & 1 & 0.672 \\
\hline & KP1 & 0.2 & $0.001^{a}$ \\
\hline & KP2 & $0.001^{\mathrm{a}}$ & $0.001^{\mathrm{a}}$ \\
\hline & KP3 & $0.01^{\mathrm{a}}$ & $0.008^{\mathrm{a}}$ \\
\hline \multirow[t]{3}{*}{ K3 } & KP1 & $0.001^{\mathrm{a}}$ & $0.001^{\mathrm{a}}$ \\
\hline & KP2 & $0.001^{\mathrm{a}}$ & $0.001^{\mathrm{a}}$ \\
\hline & KP3 & $0.001^{\mathrm{a}}$ & $0.001^{\mathrm{a}}$ \\
\hline \multirow[t]{2}{*}{ KP1 } & KP2 & 1 & 0.895 \\
\hline & KP3 & 0.202 & 0.34 \\
\hline KP2 & KP3 & 0.312 & 0.958 \\
\hline
\end{tabular}

Abbreviations: HSD, honest significant difference; FGF-2, fibroblast growth factor-2.

aSignificant at $p$-value $=0.05$.

study, it was found that MMP-9 expression tends to increase in the control group from day 4 (K1) to day 14 (K3). Alternatively, in the treatment groups, MMP-9 expression decreased from day 4 (KP1) to day 14 (KP3). This is consistent with previous studies, which found that MMP-9 expression increased from day 7 to day 14 under inflammation conditions. Orthodontic force can induce oxidative stress in the periodontal ligament that activates MMP-9. ${ }^{31}$ CAPE can reduce inflammation by inhibiting the activity of nuclear factor-kappa $\beta$ (NF-k $\beta)^{32}$ NF-k $\beta$ activation is induced by interleukin (IL)- $1 \beta$ and TNF- $\alpha$ as proinflammatory cytokine during OTM. ${ }^{1,2}$

The highest number of osteoclasts was found in the control group on day 7 (K2), while the lowest number of osteoclasts was found in the treatment group on day 14 (KP3). In this study, we were discriminated the osteoblast or osteoclast based on its morphology. Osteoclast's morphology has (1) multinucleated that attached on the bone surface with resorption area, (2) numerous mitochondria and vacuoles that can be seen in its cytoplasm; (3) ruffled border shows finger-like cytoplasmic processes (see $\boldsymbol{- F i g}$. 2). Nevertheless, tartrate-resistant acid phosphatase staining is recommended to provide better visualization for osteoclast examination during OTM. Meanwhile, osteoblast has cuboidal morphology that can be found on the interface of newly synthesized bone and strongly basophilic in their cytoplasm..$^{17,18}$

As soon as orthodontic force is applied, the inflammatory cells, osteoclasts, and osteoblast progenitors begin to appear and migrate to the afflicted periodontal tissue. The decrease in the osteoclast number is related to the lag phase. ${ }^{2}$ The formation of osteoclasts depends on the secretion of proinflammatory cytokines that is induced by OTM. ${ }^{1}$ Provision of CAPE can decrease the number of osteoclasts at days 4, 7, and 14 . This is supported by previous studies, which mention that the administration of CAPE can reduce the number of osteoclasts in the alveolar bone loss during endotoxin-induced periodontitis of an animal model. ${ }^{33}$

There were significant differences in the numbers of osteoblasts in the treatment group. CAPE contains antioxidants that inhibit the formation of ROS, resulting in osteoclastogenesis inhibition and enhancement in osteoblastogenesis. ${ }^{25}$ The increase in osteoblast numbers begins at day $7 .{ }^{16}$ In the treatment groups, osteoblasts increase significantly compared with the control group. The highest number of osteoblasts was found in the treatment group on day 14 (KP3). Salomão et al also stated that the highest osteoblast number can be found on day $14 .{ }^{15}$ The bone-defect regeneration in the animal model was significantly enhanced after CAPE provision through the antioxidant and anti-inflammatory activity that was previously reported. ${ }^{34}$

The treatment group (KP) and control group (K) showed significant differences in the expression of FGF-2 in the osteoblast. FGF-2 is a potential angiogenic growth factor that increases during wound healing. It also increases the components of the bone matrix and plays an important role in the regulation of alveolar bone remodeling..$^{13}$ In the tensile side of OTM, the expression of FGF-2 was found to increase daily from days 3 to 14 in the afflicted alveolar bone. This supports the theory that FGF-2 can induce the chemotaxis and mitogenesis of various periodontal ligament cells, thus enhancing the tissue regeneration processes. ${ }^{15} \mathrm{CAPE}$ can increase the number of collagen polymers secreted by fibroblasts. ${ }^{26}$ The administration of CAPE enhances the expression of FGF-2 and fibroblast number in diabetic animal models during traumatic ulcer wound healing. ${ }^{35}$ Additionally, the antioxidant marker such as heat shock protein-70 and the bone regeneration marker, osteocalcin expression and osteoblast number are increased but not osteoclast number after propolis extract combined with bone graft transplantation in alveolar bone defect animal model. ${ }^{36}$

One of the goals of OTM is to move and align the teeth in an efficient manner with minimum side effects in the surrounding tissues. ${ }^{37}$ To achieve the optimal OTM, alveolar bone remodeling 
homeostasis should be done. CAPE has potential antioxidant activity and anti-inflammatory ability that can promote bone formation and inhibit bone resorption. ${ }^{23,24}$ Based on our study result, CAPE provision may delay OTM rate due to inhibit the number of osteoclast and MMP-9 expression. The provision of CAPE, which is contained in propolis, may provide these healthy benefits and may become an adjuvant herbal-based therapy that suitable for relapse prevention after orthodontic treatment or OIRR prevention due to OTM excessive force.

The limitation of this study is we only conducted the immunohistochemical analysis of alveolar bone remodeling-related marker during OTM such as FGF-2 in the osteoblast and MMP-9 in the osteoclast. In our present study, we did not examine the specific marker for osteoclast or osteoblast and the OTM rate. The assessment of osteoclast and osteoblast-related specific marker should be examined in the future study such as nuclear factor-associated T cells- 1 or sclerostin for osteoclast and RUNX2 or osteocalcin for osteoblast..$^{1,10,11,18}$ In addition, OTM rate is important part to be examined to elucidate the CAPE provision effect, either inhibit or enhance the experimental OTM rate in animal model. For that reason, we suggest to examine the OTM rate in the next study. Further research is urgently needed for the analysis of mRNA level of alveolar bone remodeling and inflammatory-related marker during OTM by real-time quantitative polymerase chain reaction and signaling pathway by western blot.

\section{Conclusions}

Based on this study's results, it can be concluded that CAPE provision during OTM increases the number of osteoblasts and the FGF-2 expression significantly in the tensile side. Meanwhile, osteoclast numbers and MMP-9 expression significantly decrease during OTM after CAPE provision in the compression side, as documented immunohistochemically.

\section{Conflict of Interest}

None declared.

\section{Acknowledgments}

The authors would like to thank the financial support provided by Penelitian Unggulan Fakultas (PUF), annual activity plan budget 2020, Faculty of Dental Medicine, Universitas Airlangga, Surabaya, Indonesia with appointment number 1613/UN3.1.2/PT/2020.

\section{References}

1 Hermawan RW, Narmada IB, Djaharu'ddin I, Nugraha AP, Rahmawati D. The influence of epigallocatechin gallate on the nuclear factor associated T cell-1 and sclerostin expression in Wistar rats (Rattus norvegicus) during the orthodontic tooth movement. Res J Pharm Tech 2020;13(4):1730-1734

2 Krishnan V, Davidovitch Z. Cellular, molecular, and tissue-level reactions to orthodontic force. Am J Orthod Dentofacial Orthop 2006;129(4):469.e1-469.e32

3 Nayak BN, Galil K, Wiltshire W, Lekic PC. Molecular biology of orthodontic tooth movement. J Dent Oral Health 2013;1:1-2
4 Alhadlaq AM. Biomarkers of orthodontic tooth movement in gingival crevicular fluid: a systematic review. J Contemp Dent Pract 2015;16(7):578-587

5 Weltman B, Vig KW, Fields HW, Shanker S, Kaizar EE. Root resorption associated with orthodontic tooth movement: a systematic review. Am J Orthod Dentofacial Orthop 2010;137(4):462-476

6 Nareswari RAA, Narmada IB, Djaharu'ddin I, Rahmawati D, Putranti NAR, Nugraha AP. Effect of vitamin D administration on vascular endothelial growth factor expression and angiogenesis number in orthodontic tooth movement of pregnant Wistar rats. J Postgrad Med Inst 2019;33(3):182-188

7 Hisham PNBMB, Narmada IB, Alida A, Rahmawati D, Nugraha AP, Putranti NA. Effects of vitamin D in alveolar bone remodeling on osteoblast numbers and bone alkaline phosphatase expression in pregnant rats during orthodontic tooth movement. J Orofac Sci 2019;11:79-83

8 Nugraha AP, Narmada IB, Ernawati DS, et al. Osteogenic potential of gingival stromal progenitor cells cultured in platelet rich fibrin is predicted by core-binding factor subunit- $\alpha 1 /$ Sox 9 expression ratio (in vitro) F1000 Res 2018;7:1134

9 Nugraha AP, Narmada IB, Ernawati DS, et al. In vitro bone sialoprotein-I expression in combined gingival stromal progenitor cells and platelet rich fibrin during osteogenic differentiation. Trop J Pharm Res 2018;17(12):2341-2345

10 Sitasari PI, Narmada IB, Hamid T, Triwardhani A, Nugraha AP, Rahmawati D. East Java green tea methanolic extract can enhance RUNX2 and osterix expression during orthodontic tooth movement in vivo. J Pharm Pharmacogn Res 2020;8(4):290-298

11 Nugraha AP, Narmada IB, Ernawati DS, et al. Bone alkaline phosphatase and osteocalcin expression of rat's gingival mesenchymal stem cells cultured in platelet-rich fibrin for bone remodeling (in vitro study) Eur J Dent 2018;12(04): 566-573

12 Nugraha AP, Narmada IB, Ernawati DS, et al. Somatic cells acceleration by platelet rich fibrin. Indian Vet J 2019;96(4):30-34

13 Inayati $F$, Narmada IB, Ardani IGAW, Nugraha AP, Rahmawati D. Post oral administration of epigallocatechin gallate from Camelia sinensis extract enhances vascular endothelial growth factor and fibroblast growth factor expression during orthodontic tooth movement in Wistar rats. JKIMSU 2020;9(1):58-65

14 Fei Y, Xiao L, Doetschman T, Coffin DJ, Hurley MM. Fibroblast growth factor 2 stimulation of osteoblast differentiation and bone formation is mediated by modulation of the Wnt signaling pathway. J Biol Chem 2011;286(47):40575-40583

15 Salomão MF, Reis SR, Vale VL, Machado CV, Meyer R, Nascimento IL. Immunolocalization of FGF-2 and VEGF in rat periodontal ligament during experimental tooth movement. Dental Press J Orthod 2014;19(3):67-74

16 Holland R, Bain C, Utreja A. Osteoblast differentiation during orthodontic tooth movement. Orthod Craniofac Res 2019;22(3):177-182

17 Noguchi T, Kitaura H, Ogawa S, et al. TNF- $\alpha$ stimulates the expression of RANK during orthodontic tooth movement. Arch Oral Biol 2020;117:104796

18 Ohori F, Kitaura H, Ogawa S, et al. IL-33 inhibits TNF- $\alpha$-induced osteoclastogenesis and bone resorption. Int J Mol Sci 2020;21(3):1130

19 Li Y, Jacox LA, Little SH, Ko CC. Orthodontic tooth movement: the biology and clinical implications. Kaohsiung J Med Sci 2018;34(4):207-214

20 Bildt MM, Bloemen M, Kuijpers-Jagtman AM. Von den Hoff JW. Matrix metalloproteinases and tissue inhibitors of metalloproteinases in gingival crevicular fluid during orthodontic tooth movement. Eur J Orthod 2009;31(5):529-535 
21 Feller L, Khammissa AGR, Thomadakis G, Fourie J, Lemmer J. Apical external root resorption and repair in orthodontic tooth movement: biological events. BioMed Res Int 2016;2016(4864195) :1-7

22 Wahab RMA, Shafiai NAA, Arifin SHZ. An insight into risk factors for root resorption during orthodontic treatment. J Med Sci 2017;17(1):1-9

23 Rossi A, Ligresti A, Longo R, Russo A, Borrelli F, Sautebin L. The inhibitory effect of propolis and caffeic acid phenethyl ester on cyclooxygenase activity in J774 macrophages. Phytomedicine 2002;9(6):530-535

24 Stähli A, Maheen CU, Strauss FJ, Eick S, Sculean A, Gruber R. Caffeic acid phenethyl ester protects against oxidative stress and dampens inflammation via heme oxygenase 1. Int J Oral Sci 2019;11(1):6

25 Günay A, Arpağ OF, Atilgan S, Yaman F, Atalay Y, Acikan I. Effects of caffeic acid phenethyl ester on palatal mucosal defects and tooth extraction sockets. Drug Des Devel Ther 2014;8:2069-2074

26 Kazancioglu HO, Aksakalli S, Ezirganli S, Birlik M, Esrefoglu M, Acar AH. Effect of caffeic acid phenethyl ester on bone formation in the expanded inter-premaxillary suture. Drug Des Devel Ther 2015;9:6483-6488

27 Zawawi MS, Perilli E, Stansborough RL, et al. Caffeic acid phenethyl ester abrogates bone resorption in a murine calvarial model of polyethylene particle-induced osteolysis. Calcif Tissue Int 2015;96(6):565-574

28 Narmada IB, Husodo KRD, Ardani IGAW, Rahmawati D, Nugraha AP, Iskandar RPD. Effect of vitamin D during orthodontic tooth movement on receptor activator of nuclear factor kappa-B ligand expression and osteoclast number in pregnant Wistar rat (Rattus norvegicus) JKIMSU 2019;8(1):38-42

29 Savi FM, Brierly GI, Baldwin J, Theodoropoulos C, Woodruff MA. Comparison of different decalcification methods using rat mandibles as a model. J Histochem Cytochem 2017;65(12):705-722

30 Nugraha AP, Narmada IB, Sitasari PI, et al. High mobility group box 1 and heat shock protein-70 expression post (-)-epigallocatechin-3-gallate in East Java green tea methanolic extract administration during orthodontic tooth movement in wistar rats. Pesqui Bras Odontopediatria Clin Integr 2020;20:e5347

31 Maulana H, Hikmah N, Shita ADP, Permatasi N, Widyanti S. The effect of different orthodontic forces on MMP9 expression in a rat diabetic model. J Trop Life Sci 2014;4(2):89-95

32 Jia Y, Jiang S, Chen C, et al. Caffeic acid phenethyl ester attenuates nuclear factor-kB-mediated inflammatory responses in Müller cells and protects against retinal ganglion cell death. Mol Med Rep 2019;19(6):4863-4871

33 Kızıldağ A, Arabacı T, Albayrak M, et al. Therapeutic effects of caffeic acid phenethyl ester on alveolar bone loss in rats with endotoxin-induced periodontitis. J Dent Sci 2019;14(4):339-345

34 Uçan MC, Koparal M, Ağaçayak S, et al. Influence of caffeic acid phenethyl ester on bone healing in a rat model. J Int Med Res 2013;41(5):1648-1654

35 Puspasari A, Harijanti K, Soebadi B, Hendarti HT, Radithia D, Ernawati DS. Effects of topical application of propolis extract on fibroblast growth factor- 2 and fibroblast expression in the traumatic ulcers of diabetic Rattus norvegicus. J Oral Maxillofac Pathol 2018;22(1):54-58

36 Kresnoadi U, Rahayu RP, Ariani MD, Soesanto S. The potential of natural propolis extract combined with bovine bone graft in increasing heat shock protein 70 and osteocalcin on socket preservation. Eur J Dent 2020;14(1):31-37

37 von Böhl M, Kuijpers-Jagtman AM. Hyalinization during orthodontic tooth movement: a systematic review on tissue reactions. Eur J Orthod 2009;31(1):30-36 